\title{
Selected components of the lifestyle of adolescent girls with idiopathic scoliosis - an observational study
}

Anna Brzęk ( $\sim$ abrzek@sum.edu.pl )

Medical University of Silesia

\section{Markus Strauss}

Sector Preventive Medicine, University Witten/Herdecke

Fabian Sanchis-Gomar

Stanford University School of Medicine

Roman Leischik

Sector Preventive Medicine, University Witten/Herdecke

\section{Research Article}

Keywords: life style, physical activity, sedentary life, electronic devices, AIS, IPAQ

Posted Date: April 19th, 2021

DOI: https://doi.org/10.21203/rs.3.rs-406286/v1

License: (c) (i) This work is licensed under a Creative Commons Attribution 4.0 International License.

Read Full License 


\section{Selected components of the lifestyle of adolescent girls with idiopathic scoliosis - an ob- servational study}

Short title: Life style and AIS

Authors

Anna Brzęk ${ }^{1}$, Markus Strauss ${ }^{2,3}$, Fabian Sanchis-Gomar ${ }^{4,5}$, Roman Leischik ${ }^{2}$

Affiliations:

1. Department of Physiotherapy, Chair of Physiotherapy, School of Health Sciences, Medical University of Silesia, Katowice, Poland

2. Department of Cardiology, Sector Preventive Medicine, Health Promotion, Faculty of Health, School of Medicine, University Witten/Herdecke, 58095 Hagen, Germany

3. Department of Cardiology I-Coronary and Peripheral Vascular Disease, Heart Failure Medicine, University Hospital Muenster, Cardiol, 48149 Muenster, Germany

4. Division of Cardiovascular Medicine, Stanford University School of Medicine, Stanford, CA, USA

5. Department of Physiology, Faculty of Medicine, University of Valencia and INCLIVA Biomedical Research Institute, Valencia, Spain

Authors' e - mail addresses

Anna Brzęk - abrzek@sum.edu.pl

Markus Strauss - Markus.Strauss@uni-wh.de

Fabian Sanchis-Gomar - Fabian.sanchis@uv.es

Roman Leischik - literatur@dr-leischik.de

\section{Corresponding author (first author)}

Anna Brzęk, Assoc. Prof

School of Health Sciences in Katowice Department of Physiotherapy Chair of Physiotherapy

School of Health Sciences Medical University of Silesia in Katowice, Poland

Medyków 12 Street, 40-754 Katowice

e-mail:abrzek@sum.edu.pl, tel.number 322088721 


\section{Abstract}

Background: This research study is focused on factors affecting the level of physical activity in girls with scoliosis, looking for answers as to whether scoliosis itself is a predictive factor of motor passivity, which, as WHO indicates, is dangerous to health.

Objective: The aim of the study was to determine selected components of the lifestyle of young women with diagnosed scoliosis in confrontation with a group of women who were not diagnosed with spinal deformities.

Methods: The study consisted of a group of 82 young girls aged $16-18$ years $(x=16.9 \pm 0.81)$ with AIS (mean Cobb angle $=17.37 \pm 4.05$ ) who were who were the main group. The control group included 138 young health girls with the same ages. The girls were not diagnosed with idiopathic adolescent scoliosis and their body posture were not deviate from the norm in the sagittal, frontal and transverse planes. BMI was calculated in percentiles, and the physical activity level by IPAQ have been investigated.

Results In the studied groups of girls the level of physical activity at the moderate level dominates $(\mathrm{p}>0.05)$. There are no differences between each IPAQ domain except for the domains "Leisure/Free time" ( $\mathrm{t}=2.23 ; P=.02)$. Among the assessed factors, only BMI (A; $\mathrm{p}<0.003$ and $\mathrm{B} ; 0.0001)$, diet $(\mathrm{A} ; 0.0006$ and $\mathrm{B} ; 0.0002)$ and the use of electronic devices $(\mathrm{A} ; 0.00004$ and $\mathrm{B}$; 0.03) influence the physical activity in both groups. Place of residence, age, self acceptance, physical activity of parents and sedentary positions are not important (all $p$ values in the range $0.17-0.94)$.

Conclusion. The most important aspect of teenage girls' lifestyles is physical activity and the leisure and diet, as well as body weight. Scoliosis is not a determinant of physical activity and its level does not significantly differ between girls who are diagnosed with scoliosis and those with normal body posture, except for leisure time, which is more passive in girls with scoliosis. Overweight and abnormal eating habits affect physical activity regardless of the quality of posture. A reduction in physical activity predisposes to more frequent and increased use of electronic devices during the week.

Key words: life style; physical activity; sedentary life; electronic devices; AIS; IPAQ.

\section{Introduction}

Lifestyle as a concept or definition is difficult to classify or understand identically by different scientists, so the concept is debatable for many authors dealing with this field. In 
psychology, the term was introduced by Alfred Adler, who refers to the individual, life attitude and mental attitudes. In pedagogy and sociology, it refers to lifestyle patterns that determine social groups, place in a given group to which an individual belongs. Thorstein Veblen, on the other hand, points to lifestyles as wastefulness as a showcase of satisfaction and comfort, celebrated in the modern media world. Other theories also see the basis of lifestyle in the way of spending leisure time [1]. Still others point to the combination of lifestyle with its quality of life [2] It should also be remembered that among young people the lifestyle allows them to belong to a given social group, setting the barriers of this belonging.

A lifestyle includes several components, i.e. physical activity, leisure time, diet, health in its broad definition of mental, physical and social well-being.

Physical activity is one of the main factors in the prevention of health affecting the quality of life [3]. Insufficient of physical activity leads to a decrease in physical capacity [4], becomes a overweight or obesity [5,6], cardiovascular disorders [7] and osteoarticular disorders [8]. According to WHO recommendations, children and adolescents aged 6-17 years need an appropriate dose of physical activity for proper psychomotor development. Physical exercises should be performed regularly for at least 60 minutes a day [9]. Children and adolescents should not be exempted from obligatory PE lessons that provide the recommended dose of exercise. There are no longer any contraindications to the motor activity of patients with scoliosis, except for single contraindicated exercises depending on the level and angle of curvature and accompanying disorders in other planes. Unjustified dismissal can be a reason why these people will be less able to cope with stressful situations, and more cases of kinesiophobia [10] are noted among these people. The effects of inappropriate physical activity are well-established, and it has previously been stated that physical activity should be chosen in accordance with individual possibilities and that the consideration of individual contraindications should be considered [11]. As already mentioned, the way in which one spends his or her free time is a significant lifestyle determinant. It should be remembered that the World Health Organization points to the huge problem of sedentary society and recognises sedentary lifestyles as the fourth cause of avoidable disease deaths [12,13]. Systematic review to the data and meta analysis has synthesized the relationship between physical activity, sedentary behavior and health-related quality of life in the generally healthy population of children and adolescents $[14,15]$. The scientists suggest that participation in physical activity may support young people's current and future mental health [16]. Young people already spend a large part of their free time in a sitting position. Leisure time is another component of the lifestyle [17]. The development of civilization in the $21^{\text {st }}$ century facilitates life at school and at home for 
children and young individuals. Electronic devices are commonly used for homework. Unfortunately, the increased usage of electronic devices has negative effects, such as a reduction in physical activity $[7,18,19]$.

Scoliosis is a serious deformity of the spine, including multifaceted structural and functional abnormalities, which significantly progressively increases during adolescence. The treatment of scoliosis is long lasting, based on systematic exercises performed according to the recommendations of their proper method recommended by SOSORT, also performed at homes. Treatment outside of kinesitherapy is often combined with the additional use of a cheneau cheneau corset worn 16-22 hours/day. Asymmetries and deformations make teenagers wear wide clothes covering the body or corset. Girls isolate themselves, are ashamed of their figure, avoid physical activity and definitely spend time passively more often, which is not recommended [20].

One's health shapes pro-health behaviors and enables the development of patterns over the subsequent years [21]. One's health is particularly important when adolescence and typical physical indolence manifesting in the general reluctance to participate in any physical activities [22] is considered, especially in a group of girls.

This is how we see the issues discussed in the introduction as the aim of the study was to determine selected components of the lifestyle of young women with diagnosed scoliosis in confrontation with a group of women who were not diagnosed with spinal deformities. Research hypotheses were considered:

1. The level of physical activity of girls with scoliosis is lower than that of their healthy peers

2. Overweight and obesity are related to physical passivity

3. Motor passivity is related to the increased use of electronic devices during the week

\section{Material}

A group of 82 young girls (group A) aged $16-18$ years $(x=16.9 \pm 0.81)$ who were diagnosed with idiopathic adolescent scoliosis (AIS) on the basis of a medical examination and stitching X-rays in standing position were examined. The Cobb angle of the primary curvature ranged from $11^{\circ}$ to $25^{\circ}(\mathrm{x}=17.37 \pm 4.05 ; 95 \% \mathrm{CI}$ : 16.42-17.79), and that of the secondary curvature ranged from $8^{\circ}$ to $25^{\circ}(\mathrm{x}=13.26 \pm 3.68$; 95\%CI: $12.46-13.95)$. Girls from group A lived in the cities and countrysides in Silesian province. The control group (group B) included 138 young health girls from Silesian towns and contrysides who were aged 16-18 years 
$(x=17.09 \pm 0.78)$. The girls were not diagnosed with idiopathic adolescent scoliosis and their body posture were not deviate from the norm in the sagittal, frontal and transverse planes.

\section{Methods}

\section{Anthropometric measurements}

Body weight was assessed by medical gravity, and growth was measured as an increase in height. The measure of arm span was examined and compared with growth. There was no difference between the two groups between the two group in body weight and growth $(P>.05)$. Based on these parameters, BMI was calculated. In children and adolescents, BMI is given in percentiles $[17,18]$. Nutritional status was classified as underweight (BMI 2.3rd centile; $-2 \mathrm{SD}$ ), healthy weight (BMI $>2.3$ rd to $<85$ th centile; $>-2<+2 \mathrm{SD}$ ), overweight (BMI $\geq 85$ th $(\geq+1.05$ SD) and $<95$ th $(<1.63$ SD) centile) and obese $(\geq 95$ th centile $(\geq 1.63$ SD) $[23,24]$.

Girls from both groups performed corrective exercises (most frequently) in the form of training sessions. The characteristics of the examined groups are shown in the table below (cf. Table 1)

Table 1. Characteristics of the examined groups

\begin{tabular}{|c|c|c|c|c|c|c|c|}
\hline $\begin{array}{l}\text { GROUP } \\
(\mathbf{N})\end{array}$ & $\begin{array}{c}\text { Cobb Angle I } \\
\left(^{\circ}\right) \\
\text { Average } \\
\text { (Range) } \\
\end{array}$ & $\begin{array}{c}\text { Cobb Angle II } \\
\left({ }^{\circ}\right) \\
\text { Average } \\
\text { (Range) } \\
\end{array}$ & $\begin{array}{c}\begin{array}{c}\text { Age } \\
\text { (yr) }\end{array} \\
\text { Average } \\
\text { (Range) }\end{array}$ & $\begin{array}{c}\text { Height (m) } \\
\text { Average } \\
\text { (Range) }\end{array}$ & $\begin{array}{c}\text { ARMS' WIDTH } \\
\text { (m) } \\
\text { Average } \\
\text { (Range) }\end{array}$ & $\begin{array}{c}\text { WEIGHT } \\
\text { (kg) } \\
\text { Average } \\
\text { (Range) } \\
\end{array}$ & $\begin{array}{c}\text { BMI } \\
\text { (centile) } \\
\text { Average } \\
\text { (Range) }\end{array}$ \\
\hline A (82) & $\begin{array}{l}17.37 \pm 4.05 \\
(11-25)\end{array}$ & $\begin{array}{l}13.26 \pm 3.68 \\
(8-25)\end{array}$ & $\begin{array}{c}16.9 \pm 0.81 \\
(16-18)\end{array}$ & $\begin{array}{c}1.59 \pm 0.06 \\
(1.49-1.77)\end{array}$ & $\begin{array}{l}1.55 \pm 0.07 \\
(1.36-1.8)\end{array}$ & $\begin{array}{l}52.71 \pm 4.55 \\
(41.9-65.3)\end{array}$ & $\begin{array}{c}50.03 \pm 25.52 \\
(3-90)\end{array}$ \\
\hline B (138) & not applicable & not applicable & $\begin{array}{c}17.09 \pm 0.78 \\
(16-18)\end{array}$ & $\begin{array}{c}1.61 \pm 0.04 \\
(1.49-1.77)\end{array}$ & not applicable & $\begin{array}{c}53.87 \pm 4.35 \\
(41.9-65.0)\end{array}$ & $\begin{array}{c}52.81 \pm 25.27 \\
(3-90)\end{array}$ \\
\hline
\end{tabular}

Abbreviations: A: main group with scoliosis; B: control group; mean \pm SD followed by the min and max in brackets.

Body posture measurement

For the body posture assessment and classification, classic tools and tests were used (plumb line, scoliometer, digital inclinometer). This measurement was needed to assess the posture of the girls in the control group. Symmetry in the frontal plane and posture in the sagittal plane were evaluated. For the Sum of Angle Trank Rotation (SATR) in the transverse plane, a value not exceeding 6 degrees was assumed in the scoliometer measurement.

Physical Activity Level Questionnaire - IPAQ

The seven-day, long form International Physical Activity Questionnaire (IPAQ) was administered. The questionnaire is adapted for people between 16 and 69 years old [25]. The questions included in the survey concerned physical activity in five domains. The first one 
considered physical activity in relation to professional work (the school activities were considered to be a professional work in this group, as indicated in the questionnaire); second one - housework, third one - backyard activities; fourth one - activities related to transport and fifth one - free-time activities. Furthermore, the activities listed in the IPAQ are categorized as follows: low intensity, mainly including walking (energy output value 3.3 MET, as indicated by $\mathrm{W}$ ); moderate intensity (4.0 MET, as indicated by M); and high intensity - vigorous (8.0 MET, as indicated by V). By multiplying the number of days per week for which an activity was performed by the intensity or kind of activity described by the girls in a particular domain. The global MET/min value was calculated. Only fifth domain concerns the time spent in a sedentary position and is expressed in minutes. To classify PA by categories, the level of PA was calculated: high, for those individuals who had vigorous activity at least three days a week, with at least $1500 \mathrm{MET} \mathrm{min/week,} \mathrm{or} \mathrm{seven} \mathrm{days} \mathrm{of} \mathrm{any} \mathrm{combination} \mathrm{of} \mathrm{PA} \mathrm{reaching} \mathrm{at}$ least 3000 MET-minutes / week; moderate, for those who had three or more days of intense activity of at least 20 minutes per day, or five or more days of moderate activity, or walking of at least 30 minutes per day, or five or more days of any combination of PA reaching at least one PA total of 600 MET-minutes / week; and lastly, low level for those who did not meet the above criteria [26]. Based on the IPAQ, the level of physical activity of the girls who underwent the tests was calculated (low, moderate, vigorous) in all of the above-mentioned domains. Based on the guidelines of both the CDC (Centers for Disease Control and Prevention) and the ACSM (American College of Sports Medicine), 600 METs-min/week was set as the minimal level of physical activity to have health benefits. We defined individuals who had less than $600 \mathrm{METs}-\mathrm{min} /$ week as sedentary [27,28].

\section{Supplementary questionnaire}

The questions in the questionnaire developed by the author involved the eventual use of mobile devices, tablets, PCs, and computer games at home and at school during weekdays and weekends. The reported individual time (in minutes) referred to the amount of time that participants spent with each electronic device, separately and in total. Then the average time spent during the week and the weekend was calculated. The self-analysis questionnaire was only a supplement to the validated tool IPAQ. The questions allowed for a detailed analysis of lifestyle components, i.e. spending free time, using electronic devices or accepting your body. The questions from IPAQ concerning transport were supplemented with detailed questions concerning various means of transport. The questionnaire also included questions about exemptions from PE lessons and acceptance of your body. The data were collected in the same 
period of time between the two groups. It was important for the authors to eliminate the impact of the weather on the results obtained.

\section{Randomization}

In this investigation, individuals were excluded if they had chronic diseases (present and in the past, e.g., allergic diseases, viral infections), had cardiac diseases, had a "growth spurt" and working girls. The sample size was calculated using the sample size calculation for proportions with a margin error of $6 \%$ with a confidence level of $95 \%$ was used for a population size of 200 girls with scoliosis to yield a sample size of 115 individuals. The response rate to the distribution of the place of residence was 50\% [29]. After the exclusion criteria were considered, a total of 98 girls were included in the final calculations. 254 girls with correct body posture were randomly assigned to the control group (B), and 108 girls were finally taken into consideration. Six candidates withdrew from the group A and 4 girls from the group B after randomization. Finally group A consisted of 92 girls with scoliosis and group B included 138 girls with proper body posture.

\section{Bioethics Committee}

This study was approved by the Ethics Committee of the Medical University of Silesia in Katowice under resolution KNW-2-046/10 and KNW/0022/KB200/16. The study is in conformity with the Declaration of Helsinki. All patients and their parents/guardians provided written informed consent prior to the study, including the enrollment and data collection processes.

\section{Statistics}

The Smirnov-Kolmogorov test was used to assess the normality of the data. For data analysis, the following statistical methods were used: the Mann-Whitney U test for continuous variables with non-normal distributions and the Student's $t$ test for continuous variables with normal distributions to assess relationships between examinations, the non-parametric $\chi^{2}$ test and the Spearman's rank test. ANOVA test and Tukey post-hoc were. The relationships between the parameters were evaluated with the Pearson correlation coefficient, $\mathrm{R}$, and the $\chi^{2}$ test was used for the nonparametric characteristics. In order to determine the significant factors influencing the level of physical activity, the method of estimating Rosenbrock'a and quasi-Newtona were applied. Statistical significance was indicated when $P<.05$.

\section{Results}

\section{Lifestyle - Physical Activity Level}

The physical activity level was moderate in $32(39.5 \%)$ of the young women with scoliosis, which was the majority of the group, and it was moderate in $52(37.9 \%)$ of the girls in 
group B. In $26(32.1) \%$ of the participants in group A and in $36(26.3 \%)$ of the participants in group B, a high AF level was noted (cf. Figure 1).

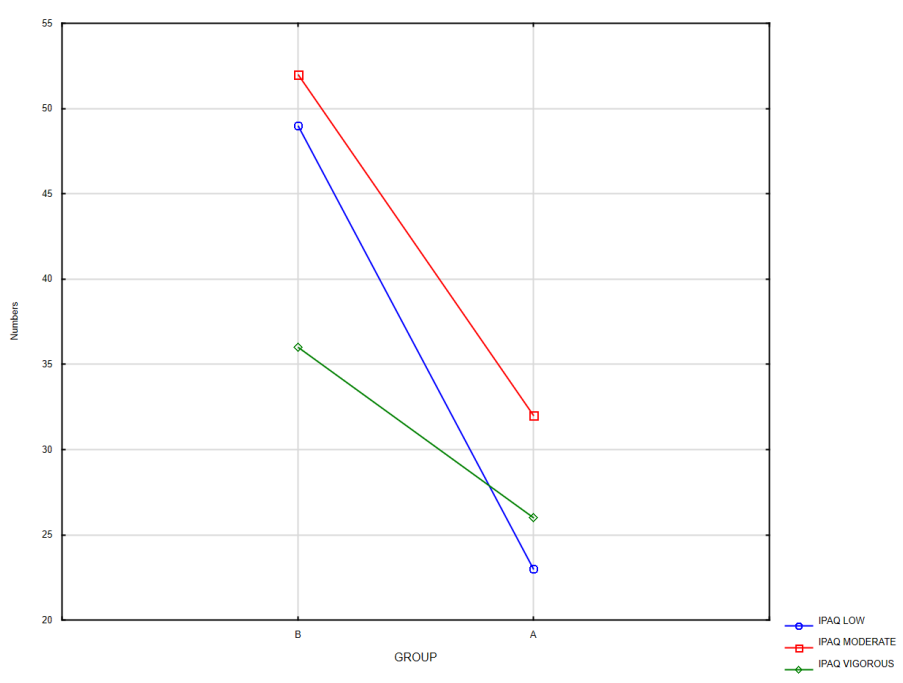

Figure 1. Physical activity level in examined groups ( $A=$ main group with AIS; $B=$ control group with normal body posture).

The level of physical activity corresponding to particular domains in the IPAQ for the examined group are shown in the table below (cf. Table 2 below). Intergroup differences with significance were observed only in the domains "Leisure/Free time" $(\mathrm{t}=2.23 ; P=.02)$.

Table 2. Level of physical activity of examined group in particular domains included in the IPAQ

\begin{tabular}{|c|c|c|c|c|c|c|c|}
\hline \multirow{2}{*}{ IPAQ DOMAIN } & \multicolumn{3}{|c|}{ Main A (82) } & \multicolumn{3}{|c|}{ Control B (138) } & \multirow{2}{*}{ P Value* } \\
\hline & $\begin{array}{l}\text { Average } \pm \text { SD } \\
\quad \text { (Range) }\end{array}$ & Me & $95 \mathrm{CI}$ & $\begin{array}{l}\text { Average } \pm \text { SD } \\
\text { (Range) }\end{array}$ & Me & $95 \mathrm{CI}$ & \\
\hline $\begin{array}{l}\text { JOB - RELATED } \\
\text { (MET-min/week) }\end{array}$ & $\begin{array}{c}1321.47 \pm 1301.79 \\
(0-5040)\end{array}$ & 1476 & $\begin{array}{c}1143.67- \\
1565.25\end{array}$ & $\begin{array}{c}1518.76 \pm 1408.61 \\
(0-5040)\end{array}$ & 1425 & $\begin{array}{c}1259.61- \\
1598.48\end{array}$ & $1.11^{1}$ \\
\hline $\begin{array}{l}\text { HOUSEWORK } \\
\text { (MET-min/week) }\end{array}$ & $\begin{array}{c}1896.79 \pm 1718.64 \\
(0-5640)\end{array}$ & 1410 & $\begin{array}{l}1488.65- \\
2033.34\end{array}$ & $\begin{array}{c}1698.86 \pm 1631.77 \\
(0-5720)\end{array}$ & 1260 & $\begin{array}{c}1458.74- \\
1851.73\end{array}$ & $0.84^{2}$ \\
\hline $\begin{array}{l}\text { TRANSPORTATION } \\
\text { (MET-min/week) }\end{array}$ & $\begin{array}{c}1768.23 \pm 1285.67 \\
(0-4752)\end{array}$ & 1650 & $\begin{array}{c}1112.69 \\
1522.84\end{array}$ & $\begin{array}{c}1606.93 \pm 1270.87 \\
(0-4752)\end{array}$ & 1188 & $\begin{array}{c}1135.23- \\
1443.63\end{array}$ & $0.89^{1}$ \\
\hline $\begin{array}{l}\text { LEISURE - TIME } \\
\text { (MET-min/week) }\end{array}$ & $\begin{array}{c}1468.37 \pm 1569.62 \\
(99-6799)\end{array}$ & 693 & $\begin{array}{c}1359.58- \\
1857.04\end{array}$ & $\begin{array}{c}2016.05 \pm 1845.77 \\
(0-7200)\end{array}$ & 1386 & $\begin{array}{c}1650.08- \\
2094.61\end{array}$ & $2.23 * * 1$ \\
\hline $\begin{array}{l}\text { AVERAGE TIME } \\
\text { SITTING (min/day) }\end{array}$ & $\begin{array}{r}313.43 \pm 145.91 \\
(72-600)\end{array}$ & 300 & $\begin{array}{c}126.39- \\
172.63\end{array}$ & $\begin{array}{l}301.18 \pm 151.01 \\
\quad(70-900)\end{array}$ & 285.71 & $\begin{array}{c}134.99- \\
171.35\end{array}$ & $0.55^{2}$ \\
\hline $\mathrm{MET} / \mathrm{min} /$ week & $\begin{array}{c}7362.03 \pm 3073.36 \\
(495-10200) \\
\end{array}$ & 8475.0 & $\begin{array}{l}2647.1- \\
3615.66 \\
\end{array}$ & $\begin{array}{c}7301.55 \pm 3165.67 \\
(600-11100) \\
\end{array}$ & 8940 & $\begin{array}{l}2812.5- \\
3570.17 \\
\end{array}$ & $0.89^{2}$ \\
\hline
\end{tabular}

Data are the mean \pm SD: standard deviation and range; ${ }^{*}$ P-value according to ${ }^{1}$ Mann-Whitney $U$ test for continuous variables with nonnormal distributions, ${ }^{2}$ Student's t-test for continuous variables with normal distributions; *p $<0.05,{ }^{* *} \mathrm{p}<0.01$

Abbreviations: A: main group; B: control group; IPAQ: International Physical Activity Questionnaire, METs: Metabolic Equivalent of Work per Week/minutes. 
The occurrence of scoliosis does not predispose to reduce physical activity in this age group of girls $\left(\mathrm{X}^{2}=0.21, \mathrm{p}=0.64, \mathrm{df}=2\right)$. Table 3 and 4 shows the results of logistic regression analysis with scoliosis as the main outcome variable and the level of physical activity.

Table 3 Factors influencing the physical activity of 82 girls with scoliosis

\begin{tabular}{lcccc}
\hline \multicolumn{1}{c}{ Variables } & $\mathbf{X}^{2}$ Walda & Odds Ratio (OR) & 95\% CI & P Value \\
\hline Age (yr) & 0.16 & 1.14 & $0.57-2.27$ & 0.69 \\
Residence & 0.83 & 2.02 & $0.43-9.38$ & 0.36 \\
BMI (percentiles) & 14.9 & 1.14 & $1.01-1.05$ & $0.003^{*}$ \\
PE exemption & 0.32 & 0.81 & $0.41-1.64$ & 0.56 \\
Accept yourself & 0.21 & 0.87 & $0.51-1.53$ & 0.64 \\
Complexes & 1.82 & 0.63 & $0.32-1.24$ & 0.17 \\
Diet & 2.34 & 0.36 & $0.08-1.38$ & $0.0006^{*}$ \\
Using of electronic devices & 16.76 & 0.99 & $0.87-0.97$ & $0.00004^{*}$ \\
Sedentary positions & 0.68 & 1.01 & $0.99-1.0$ & 0.41 \\
Parents'PA & 0.33 & 0.74 & $0.26-2.09$ & 0.56 \\
\hline
\end{tabular}

Abbreviations: yr: years; CI: confidence interval; PA: Physical Activity.

Table 4 Factors influencing the physical activity of 138 girls with control group

\begin{tabular}{lcccc}
\hline \multicolumn{1}{c}{ Variables } & $\mathbf{X}^{\mathbf{2}}$ Walda & Odds Ratio (OR) & $\mathbf{9 5 \%}$ CI & P Value \\
\hline Age (yr) & 0.2 & 1.11 & $0.68-1.84$ & 0.65 \\
Residence & 0.005 & 1.03 & $0.48-2.19$ & 0.94 \\
BMI (percentiles) & 18.17 & 1.04 & $1.01-1.05$ & $0.0001^{*}$ \\
PE exemption & 0.22 & 0.38 & $0.07-2.33$ & 0.63 \\
Accept yourself & 0.77 & 0.73 & $0.36-1.47$ & 0.37 \\
Complexes & 0.02 & 0.97 & $0.68-1.38$ & 0.87 \\
Diet & 6.59 & 0.41 & $0.2-0.81$ & $0.0002^{*}$ \\
Using of electronic devices & 4.73 & 0.61 & $0.87-0.97$ & $0.03^{*}$ \\
Sedentary positions & 0.33 & 1.0 & $0.99-1.01$ & 0.56 \\
Parents' PA & 0.04 & 1.02 & $0.47-2.2$ & 0.94 \\
\hline
\end{tabular}

Abbreviations: yr: years; CI: confidence interval; PA: Physical Activity.

In the following, we focus only on those factors that influence girls' physical activity: BMI, diet, using of electronic devices. The others were described in the discussion section.

Lifestyle - BMI and diets

BMI in the percentiles was within the limit of the correct control group in $76.8 \%$ and in $76.09 \%$ of the control group. The remaining girls were within the range BMI $\geq 85$ th and $<95$ th. None of the girls were obese.

Girls of both groups were overwhelmed by regular food. However, the girls in the control group ate unhealthy snacks more often $(\mathrm{p}<0.001)$, most often during their studies or leisure time. Active girls with normal body weight eats healthy regardless of the deformation of the spine. Their diet contained an advantage of fruit and vegetables (cf. figure 2) . 


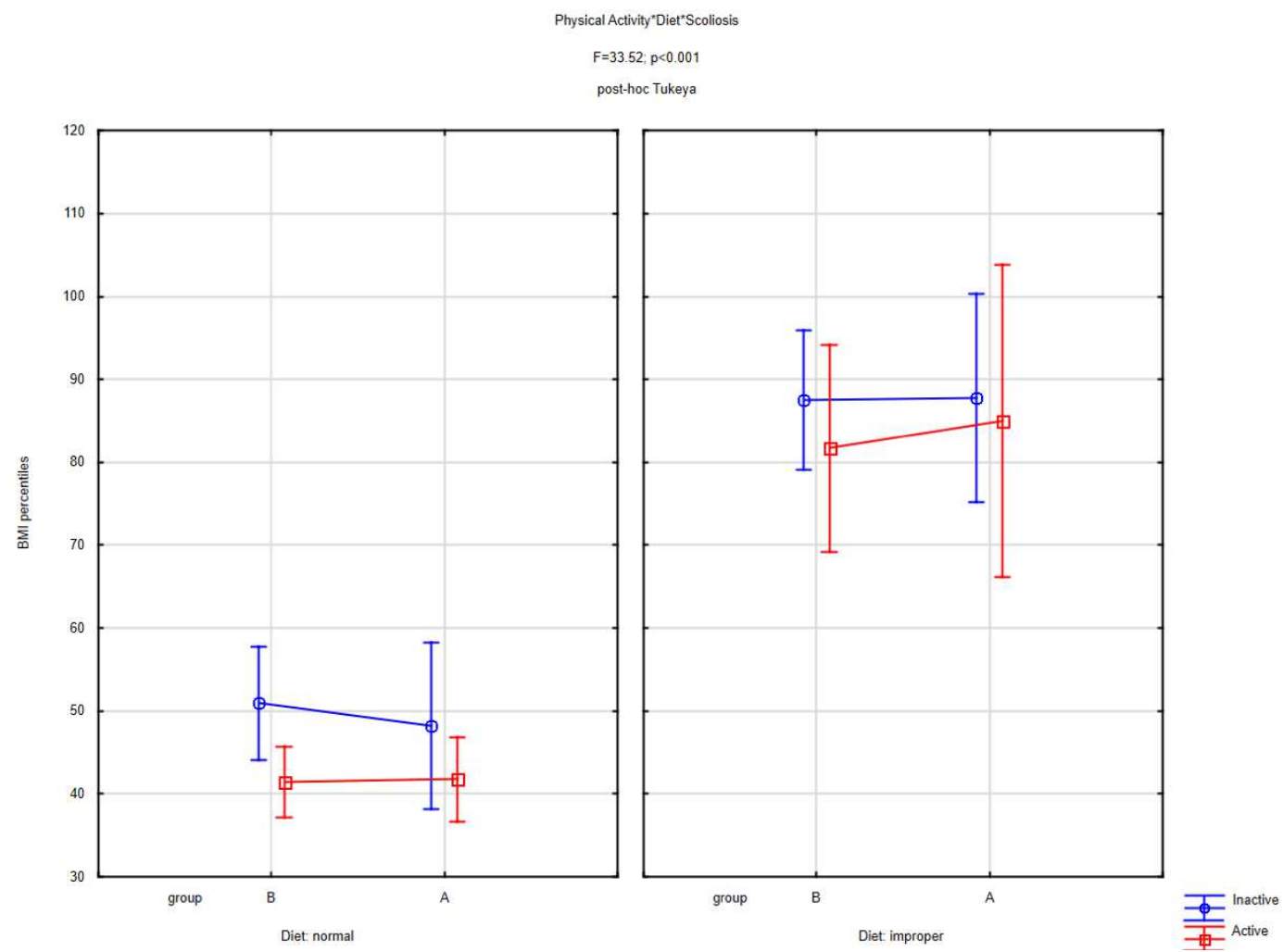

Figure 2. Average of BMI and interaction graphs of averages and interactions of factors such as scoliosis, physical activity levels and diet (analysis of variance ANOVA).

Slightly more than $15 \%$ of group A and $5 \%$ of group B were vegetarians. They were girls with a relatively high level of physical activity. $43 \%$ of girls in group A were ever on a weight loss diet in confrontation with girls in group B, where only $22 \%$ of the examined girls admitted to the diet.

\section{Lifestyle - electronic devices}

The examined girls in both groups reported using electronic devices regularly each day. There were no significant differences between the girls in both groups $(P=.97)$. The usage time of electronic devices ranged between 3 and 7 days per week. The number of hours in front of a TV, computer, tablet or mobile device was neutral for girls in both groups and ranged between 60 and 1560 minutes per week $\left(95 \% \mathrm{CI}_{\mathrm{A}}\right.$ : 326.27-444.77 for M:990 and 95\% $\mathrm{CI}_{\mathrm{B}}$ : 339.42-432.02 for M: 962). All inactive groups, regardless of body posture quality and weight, were not different in time of using electronic devices with an average of 1228$1314 \mathrm{~min} /$ week. All inactive groups, regardless of posture quality and weight, did not differ in terms of time of use of electronic devices, using an average of 1228-1314 min/week. In contrast, the active groups used these devices much shorter in the range of $627.8-877.39$ $\mathrm{min} /$ week. (cf. figure 3). 


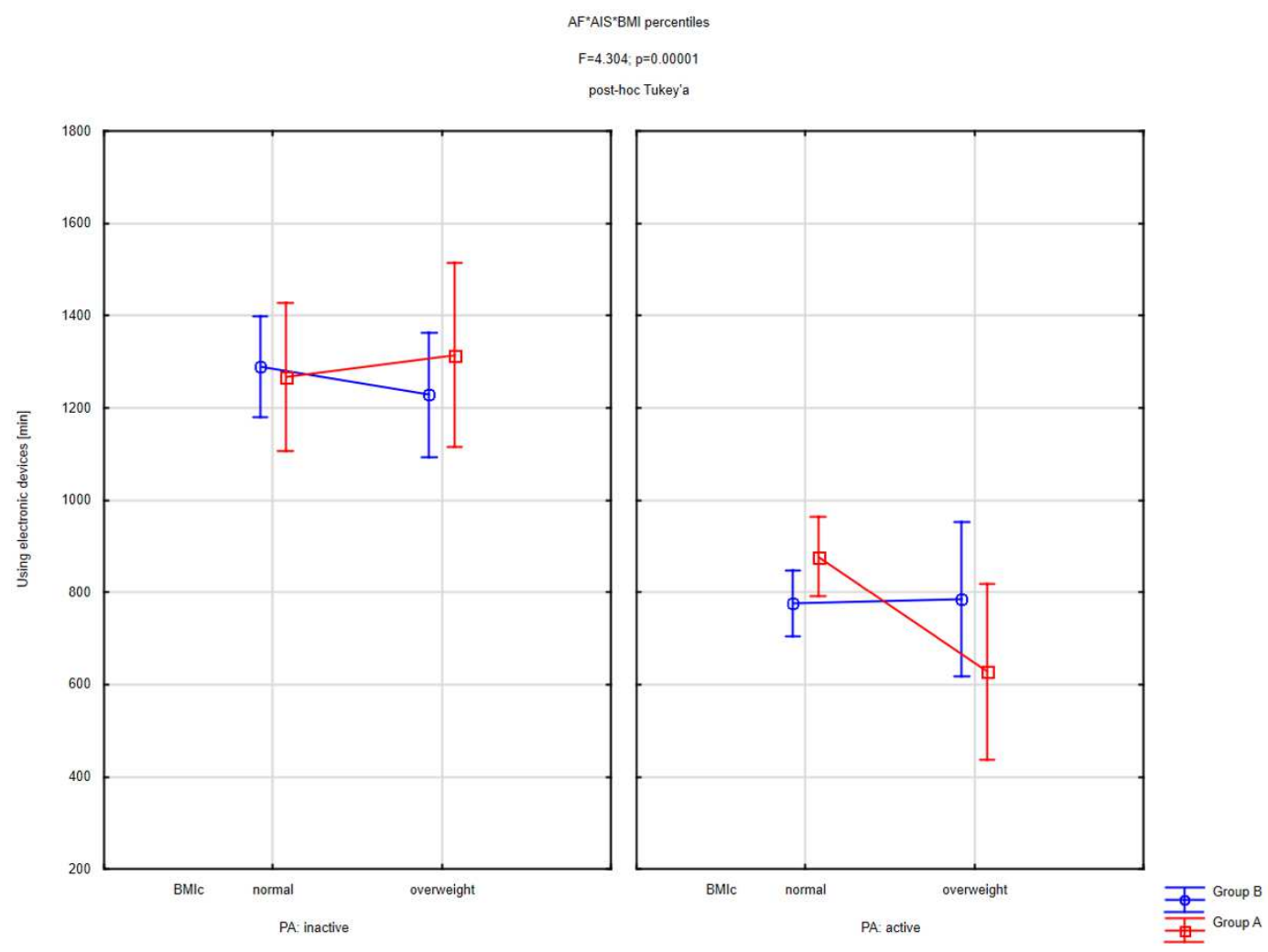

Figure 3. Average of time of using electronic devices and interaction graphs of averages and interactions of factors such as scoliosis, physical activity levels and BMI (analysis of variance ANOVA)

\section{Discussion}

The study was conducted to assess the lifestyle of girls in adolescence. Age was chosen deliberately, because it is during this period that the social aspect is of great importance in taking up or not taking up physical activity, the way of spending free time and acceptance of health or body level. This age is also an extremely important period, one could say the final one, shaping the body posture in the physical aspect. Scoliosis is a deformity of the spine, noticeable by the environment of peers, often not accepted by the patient himself. The modern world of development of new information technologies, on the one hand, encourages the young generation to abuse electronic equipment and thus to spend time in a sitting position. On the other hand, however, it is important to remember about the negative effects of motor passivity, especially for people with scoliosis. Therefore, this group seemed to the authors to be extremely important in assessing the level of physical activity and searching for the determinants of active leisure activities.

The research presented in this study is part of a large scientific project being conducted by the author. The project involves more than 1300 children from the Silesia Region in Poland. According to Pokrywka et al. [30], the prevalence of posture disorders is $38-39 \%$ in 
Polish children. Five percent of these patients suffer from bad body posture and severe spine deformities, such as scoliosis [31]. Scoliosis more often involves girls. Therefore, the number of girls with scoliosis is smaller in the control group.

The study was dedicated to girls as the research indicates a reduction in physical activity among girls during adolescence [32] here the average annual reduction in total physical activity from the age of 5 to 18 years is $4.6 \%$ [33]. Importantly, physical activity habits adopted during adolescence track into adulthood [34,35] and may affect the likelihood of developing many chronic health conditions.

Gordon-Larsen P et. all indicate that PE classes may represent the only opportunity for many adolescents to engage in weekly physical activity. Conversely, the number of PE classes per week was not associated with level of inactivity of these adolescents [36]. In the own study, the percentage of girls completely exempt from the PE lessons was $20.9 \%$ of girls with scoliosis and $7.25 \%$ of girls from the control group. The girls pointed out that the PE teachers did not know what to do with partial exemptions, so they themselves suggested total exemptions. It should be remembered that an adequate daily dose of exercise is essential for proper psychomotor development, including posture formation during posturogenesis [3,9].

Researchers dealing with scoliosis indicate that the SOSORT guidelines indicate that it is not necessary, or even dangerous, to exempt girls with scoliosis from physical education classes in daily practice. SOSORT also recommends patients with scoliosis to remain active in sports activities, especially since participation does not seem to affect the occurrence or degree of scoliosis [20]. In addition, in a recent cross-sectional study by Zaina et al., tennis was found not to be correlated with spine deformities [37]. It is recommended that if the scoliosis is combined with a flat back or in the case of large deformities, a waiver of some exercises be considered. This approach seems reasonable [38]. Physical education plays a particularly important role in the development of health-promoting behaviour. Physical education plays a particularly important role in shaping pro-health behaviors [39]. According to Leischik [40], physical education should be defined as a "health factory", and fitness and physical efficacy are its products.

In our own research it was found that scoliosis is not a determinant of an active lifestyle. This fact was found to be satisfactory. It may indicate a high level of education in this field conducted by physiotherapists during the period of improving scoliosis.

Scientific research indicates the influence of scoliosis on the quality of life in long-term observation, therefore it is worth remembering about it in everyday practice [41]. In this study the lower level of AF in the group of girls with scoliosis was recorded only in the leisure do- 
main. This phenomenon can be explained by the fact that this part does not include exercises undertaken by girls within the framework of scoliosis therapy, which took place systematically 1-2 times a week for 45-60 minutes. Girls did not treat corrective exercises as free time but as an obligation planned during the week.

The BMI coefficient calculated in centiles and the related girls' diet also proved to be the predictor of physical activities. The research confirmed the results obtained by numerous researchers on physical passivity among overweight and obese youth. Glinkowski's research indicates the role of prevention programs in overweight and obese children and adolescents [42].

Another factor influencing systematic physical exercise is the increased use of electronic devices [7,17], which, combined with an increase in body weight, results in an even greater reduction in the level of physical activity. The Health Behaviour in School-aged Children (HBSC) suggests spending less than two hours per day in screen-based sedentary behaviors [2]. The examined girls spent much more time with electronic devices. Similar observations were indicated by researchers Iannotti et all and Chinapaw et al. [22,29]. The occurrence of scoliosis was irrelevant. In spite of the world-wide theory of the sedentary world, we found that the studied group spent 60-900 minutes per week in a sitting position regardless of the occurrence of scoliosis. The use of Internet applications by young people can support their health knowledge, especially during periods of reduced physical activity associated with illness or temporary isolation caused by e.g. a pandemic $[43,44]$.

The authors were surprised by the fact that there was no correlation between the physical activity of adolescents and the AF level of their parents, which was noticeable in other studies by the first author concerning younger children [45] This fact can be explained by the changing authorities of parents in adolescents in favour of their peers, idols shaped by the media. This is related to adolescence and the converging period of rebellion. Although this aspect is very different in scientific research [46,47].

The place of residence, age, self-acceptance of the body or indication of complexes were not related to systematic physical activity. Research conducted by Cristina M Caperchione et. al has shown that adolescents are highly susceptible to negative self-perceptions, likely due to their social cues and environment [48]. The presence of these negative selfperceptions has been shown to adversely impact levels of physical activity (PA). Several studies have suggested that increased physical activity participation is associated with a more positive body image among adolescent girls [49,50,51]. Such a tendency was noticed in our own research, but it was statistically insignificant in the compared groups of girls. 
The concluding statement is that the Health Behaviour in School-aged Children (HBSC) points to the ongoing discussion on defining healthy lifestyles, it is clear that a complex measurement that combines healthy behaviors (i.e. engaging in physical activity every day, limiting the use of electronic devices, eating fruit and vegetables every day, and avoiding alcohol and tobacco) reflects a variable that is related to better health. This is in line with the results of this study and the fact that these health-related behaviors are among the most important health-related ones. Clearly, the need to promote healthy movement behaviours among children and youth is a world-wide public health priority [2,52].

The limitation of study might be the size of the group and the lack of a detailed quality of life analysis based on a validated questionnaire to one which is dedicated, although the study had a different approach to begin with. The analysis of the results showed that indicating the mental and physical components of quality of life would be complementary to the analysis.

\section{Conclusions}

The most important lifestyle aspect of adolescent girls is physical activity and the way of spending free time directly related to it, as well as diet and body weight. Scoliosis in itself is not a determinant of the physical activity undertaken and its level does not differ between girls who are diagnosed with this serious spinal deformity such as scoliosis and those whose posture is considered to be appropriate. The only exception is leisure time, which is more passive among girls with scoliosis. Overweight and abnormal eating habits have an impact on physical activity regardless of the body posture quality. Decreasing physical activity to a moderate or ordinary level predisposes to more frequent and longer use of electronic devices during the week. From a practical point of view, active leisure activities should be promoted among young people as the most important component influencing the lifestyle.

\section{Abbreviations}

AIS: Adolescent Idiopathic Scoliosis; IPAQ: International Physical Activity questionnaire; BMI: Body Mass Index; CDC: Centers for Disease Control and Prevention; ACSM: American College of Sports Medicine; HBSC: The Health Behaviour in School-aged Children

\section{Authors' Contributions}


$\mathrm{AB}$ conceived, designed and performed the experiment. $\mathrm{AB}, \mathrm{RL}$ and MS analyzed the data. $\mathrm{AB}$ and FG contributed reagents/materials/analysis tools. AB, RL, MS and FG contributed to the writing of the manuscript. $\mathrm{AB}$ revised the tables and figures. $\mathrm{AB}$ and $\mathrm{FG}$ revised the references. AB and RL revised the manuscript critically. All authors approved final version of manuscript.

\section{Funding}

Not applicable.

\section{Availability of data and materials}

The datasets used and/or analyzed during the current study are available from the corresponding author on reasonable request.

\section{Declarations}

Not applicable.

\section{Acknowledgements}

Not applicable.

\section{Ethics approval and consent to participate}

This study was approved by the Ethics Committee of the Medical University of Silesia in Katowice under resolution KNW-2-046/10 and KNW/0022/KB200/16. The study is in conformity with the Declaration of Helsinki. All patients and their parents/guardians provided written informed consent prior to the study, including the enrollment and data collection processes.

\section{Consent for publication}

Not applicable.

\section{Competing interests}

The authors declare that they have no competing interests.

\section{References:}

1. Florida R. The Rise of the Creative Class, And How It's Transforming Work, Leisure, Community and Everyday Life. Journal of Regional Science. 2003,2,43.

2. Marques A, Demetriou Y, Tesler R, Gouveia ÉR, Peralta M, Matos MG. Healthy Lifestyle in Children and Adolescents and Its Association with Subjective Health Complaints: Findings from 37 Countries and Regions from the HBSC Study. Int J Environ Res Public Health. 2019;16(18):3292. Published 2019 Sep 7. doi:10.3390/ijerph16183292 
3. World Health Organization. Physical Activity: Global recommendations on physical activity for health Consequences of physical inactivity. WHO Reg Off Eur. 2015. doi:ISBN 9789241599979

4. Salonen MK, Wasenius N, Kajantie E, et al. Physical activity, body composition and metabolic syndrome in young adults. PLoS One. 2015. doi:10.1371/journal.pone.0126737

5. Dias KA, Green DJ, Ingul CB, Pavey TG, Coombes JS. Exercise and vascular function in child obesity: A meta-analysis. Pediatrics. 2015. doi:10.1542/peds.2015-0616

6. Leischik R, Foshag P, Strauss M, et al. Physical activity, cardiorespiratory fitness and carotid intima thickness: Sedentary occupation as risk factor for atherosclerosis and obesity. Eur Rev Med Pharmacol Sci. 2015.

7. Ekelund U, Luan J, Sherar LB, Esliger DW, Griew P, Cooper A. Moderate to vigorous physical activity and sedentary time and cardiometabolic risk factors in children and adolescents. JAMA - J Am Med Assoc. 2012. doi:10.1001/jama.2012.156

8. de Vasconcelos GAR, Fernandes PRB, de Oliveira DA, Cabral ED, da Silva LVC. Postural evaluation of vertebral column in deaf school kids from 7 to 21 years old. Fisioter em Mov. 2010.

9. Global recommendations on physical activity for health. Geneva. World Health Organization. WHO Press, 2010 (Accessed February 23, 2012. whqlibdoc.who.int/publications/2010/9789241599979_eng.pdf.

10. Knapik A, Saulicz E, Gnat R. Kinesiophobia - Introducing a new diagnostic tool. J Hum Kinet. 2011. doi:10.2478/v10078-011-0019-8

11. Knapik A, Saulicz E, Kuszewski M, Plinta R. An Analysis of Relations Between a Self-Assessment of Health and Active Life-Style. Med Sport. 2009. doi:10.2478/v10036-009-0004-7

12. Health Topics: Physical Activity, World Health Organization, www.who.int/topics/physical_activity/en/.

13. Starrett K, Starrett J and Cordoza G. Skazany na biurko. Postaw się siedzącemu światu. Galaktyka, Łódź, 2016.

14. $\mathrm{Wu} \mathrm{XY}$, Zhuang $\mathrm{LH}, \mathrm{Li} \mathrm{W}$, et al. The influence of diet quality and dietary behavior on health-related quality of life in the general population of children and adolescents: a systematic review and meta-analysis. Qual Life Res. 2019;28(8):1989-2015. doi:10.1007/s11136-019-02162-4 
15. Bermejo-Cantarero A, Álvarez-Bueno C, Martinez-Vizcaino V, García-Hermoso A, Torres-Costoso AI, Sánchez-López M. Association between physical activity, sedentary behavior, and fitness with health related quality of life in healthy children and adolescents: A protocol for a systematic review and meta-analysis. Medicine (Baltimore). 2017;96(12):e6407. doi:10.1097/MD.0000000000006407

16. Rodriguez-Ayllon M, Cadenas-Sánchez C, Estévez-López F, et al. Role of Physical Activity and Sedentary Behavior in the Mental Health of Preschoolers, Children and Adolescents: A Systematic Review and Meta-Analysis. Sports Med. 2019;49(9):1383-1410. doi:10.1007/s40279-019-01099-5

17. Sherar LB, Griffin TP, Ekelund U, et al. Association between maternal education and objectively measured physical activity and sedentary time in adolescents. J Epidemiol Community Health. 2016;70:541-8.

18. Fernández I, Canet O, Giné-Garriga M. Assessment of physical activity levels, fitness and perceived barriers to physical activity practice in adolescents: cross-sectional study. Eur J Pediatr. 2017. doi:10.1007/s00431-016-2809-4

19. Javed A, Jumean M, Murad MH, et al. Diagnostic performance of body mass index to identify obesity as defined by body adiposity in children and adolescents: A systematic review and meta-analysis. Pediatr Obes. 2015. doi:10.1111/ijpo.242

20. Negrini S, Donzelli S, Aulisa AG, et al. 2016 SOSORT guidelines: orthopaedic and rehabilitation treatment of idiopathic scoliosis during growth. Scoliosis Spinal Disord. 2018;13:3. Published 2018 Jan 10. doi:10.1186/s13013-017-0145-8

21. Brzek A, Plinta R. Exemplification of movement patterns and their influence on body posture in younger school-age children on the basis of an authorial program " $i$ take care of my Spine.” Med (United States). 2016. doi:10.1097/MD.0000000000002855

22. Iannotti RJ, Janssen I, Haug E, et al. Interrelationships of adolescent physical activity, screen-based sedentary behaviour, and social and psychological health. Int J Public Health. 2009. doi:10.1007/s00038-009-5410-z

23. Cole TJ. The LMS method for constructing normalized growth standards. Eur J Clin Nutr 1990;44:45e60.

24. Cole TJ, Freeman JV, Preece MA. Body mass index reference curves for the UK, 1990. Arch Dis Child 1995;73:25e9.

25. Haskell WL, Lee IM, Pate RR, et al. Physical activity and public health: Updated recommendation for adults from the American College of Sports Medicine and the Amer- 
ican Heart Association. Med Sci Sports Exerc. 2007. doi:10.1249/mss.0b013e3180616b27

26. Booth M. Assessment of Physical Activity: An International Perspective. Research Quarterly for Exercise and Sport. [Internet]. 2000 [cited April 30, 2016]; 71(2): s11420. Available from: https://www. ncbi.nlm.nih.gov/pubmed/10925833

27. Pate RR, Pratt M, Blair SN, Haskell WL, Macera CA, Bouchard C, et al. Physical activity and public health. A recommendation from the Cen- ters for Disease Control and Prevention and the American College of Sports Medicine. JAMA 1995;273:402-407.

28. Arem H, Moore SC, Patel A, Hartge P, De Gonzalez AB, Visvanathan K, et al. Leisure time physical activity and mortality: a detailed pooled anal- ysis of the doseresponse relationship. JAMA Intern Med 2015;175:959- 22. 967.

29. Chinapaw M, Altenburg T, Brug J. Sedentary behaviour and health in children - Evaluating the evidence. Prev Med (Baltim). 2015. doi:10.1016/j.ypmed.2014.10.029

30. Konieczny MR, Senyurt H, Krauspe R. Epidemiology of adolescent idiopathic scoliosis. J Child Orthop. 2013. doi:10.1007/s11832-012-0457-4

31. Raosoft. Inc, Sample size calculator. US. 2004. www.raosoft.com/samplesize.html. . Published 2004. Accessed May 12, 2017.

32. Allison KR, Adlaf EM, Dwyer JJM, Lysy DC, Irving HM. The decline in physical activity among adolescent students: a cross-national comparison. Can J Public Health. 2007;98:97-100. doi: 10.1007/BF03404317.

33. Cooper AR, Goodman A, Page AS, Sherar LB, Esliger DW, van Sluijs EMF, et al. Objectively measured physical activity and sedentary time in youth: the International children's accelerometry database (ICAD) Int J Behav Nutr Phys Act. 2015;12:113. doi: 10.1186/s12966-015-0274-

34. elama R. Tracking of physical activity from childhood to adulthood: a review. Obes Facts. 2009;2:187-195. doi: 10.1159/000222244.

35. Hayes G, Dowd KP, MacDonncha C, Donnelly AE. Tracking of physical activity and sedentary behavior from adolescence to Young adulthood: a systematic literature review. J Adolesc Health. 2019. 10.1016/j.jadohealth.2019.03.013.

36. Gordon-Larsen P, McMurray RG, Popkin BM. Determinants of adolescent physical activity and inactivity patterns. Pediatrics. 2000. doi:10.1542/peds.105.6.e83

37. Zaina F, Donzelli S, Lusini M, Fusco C, Minnella S, Negrini S. Tennis is not dangerous for the spine during growth: results of a cross-sectional study. Eur Spine J. 2016 Sep; 25(9):2938-44. 
38. Athanasopoulos S, Paxinos T, Tsafantakis E, Zachariou K, Chatziconstantinou S. The effect of aerobic training in girls with idiopathic scoliosis. Scand J Med Sci Sports. 1999 Feb; 9(1):36-40.

39. Lobstein T, Jackson-Leach R, Moodie ML, et al. Child and adolescent obesity: Part of a bigger picture. Lancet. 2015. doi:10.1016/S0140-6736(14)61746-3

40. Leischik R, Dworrak B, Strauss M, et al. Plasticity of Health. Heal Ger J Med. 2016. doi:10.19209/GJOM000001

41. Simony A, Hansen EJ, Carreon LY, Christensen SB, Andersen MO. Health-related quality-of-life in adolescent idiopathic scoliosis patients 25 years after treatment. Scoliosis. $2015 ; 10(): 22$.

42. Glinkowska B, Glinkowski WM. Association of sports and physical activity with obesity among teenagers in Poland. Int J Occup Med Environ Health. 2018 Dec 20;31(6):771-782. doi: 10.13075/ijomeh.1896.01170. Epub 2018 Nov 22. PMID: 30484439 .

43. Park E, Kwon M. Health-Related Internet Use by Children and Adolescents: Systematic Review. J Med Internet Res. 2018 Apr 3;20(4):e120. doi: 10.2196/jmir.7731. PMID: 29615385; PMCID: PMC5904452.

44. Cueto V, Wang CJ, Sanders LM. Impact of a Mobile App-Based Health Coaching and Behavior Change Program on Participant Engagement and Weight Status of Overweight and Obese Children: Retrospective Cohort Study. JMIR Mhealth Uhealth. 2019 Nov 15;7(11):e14458. doi: 10.2196/14458. PMID: 31730041; PMCID: PMC6884716.

45. Brzęk A, Sołtys J, Gallert-Kopyto W, Gwizdek K, Plinta R. Body posture in children with obesity - the relationship to physical activity (PA). Pediatr Endocrinol Diabetes Metab. 2016;22(4):148-155. doi: 10.18544/PEDM-22.04.0063. PMID: 29073297.

46. Voelker D., Reel J., Greenleaf C. Weight Status and Body Image Perceptions in Adolescents: Current Perspectives. Adolesc. Health. Med. Ther. 2015;6:149-158. doi: 10.2147/ahmt.s68344.

47. Tiggemann M, Slater A. Netgirls: the internet, facebook, and body image concern in adolescent girls. Int J Eat Disord. 2013;46(6):630-633. 10. Meier EP, Gray J. Facebook photo activity associated with body image disturbance in adolescent girls. Cyberpsychol Behav Soc Netw. 2014; 17(4):199-206.

48. Caperchione CM, Hargreaves N, Sabiston CM, Berg S, Kowalski KC, Ferguson LJ. Exploring the Effectiveness of an Integrated Physical Activity and Psychosocial Pro- 
gram Targeting At-Risk Adolescent Girls: Protocol for the Girls United and on the Move (GUM) Intervention Study. JMIR Res Protoc. 2020;9(6):e15302. Published 2020 Jun 9. doi:10.2196/15302

49. Añez E., Fornieles-Deu A., Fauquet-Ars J., López-Guimerà G., Puntí-Vidal J., Sánchez-Carracedo D. Body Image Dissatisfaction, Physical Activity and ScreenTime in Spanish Adolescents. J. Health Psychol. 2018;32:36-47. doi: $10.1177 / 1359105316664134$.

50. Kantanista A., Osiński W., Borowiec J., Tomczak M., Król-Zielińska M. Body Image, BMI, and Physical Activity in Girls and Boys Aged 14-16 Years. Body Image. 2015;15:40-43. doi: 10.1016/j.bodyim.2015.05.001

51. Schneider S., Weiß M., Thiel A., Werner A., Mayer J., Hoffmann H., Diehl K. Body Dissatisfaction in Female Adolescents: Extent and Correlates. Eur. J. Pediatr. 2013;172:373-384. doi: 10.1007/s00431-012-1897-z.

52. Rhodes RE, Guerrero MD, Vanderloo LM, et al. Development of a consensus statement on the role of the family in the physical activity, sedentary, and sleep behaviours of children and youth. Int J Behav Nutr Phys Act. 2020;17(1):74. Published 2020 Jun 16. doi:10.1186/s12966-020-00973-0 
Figures

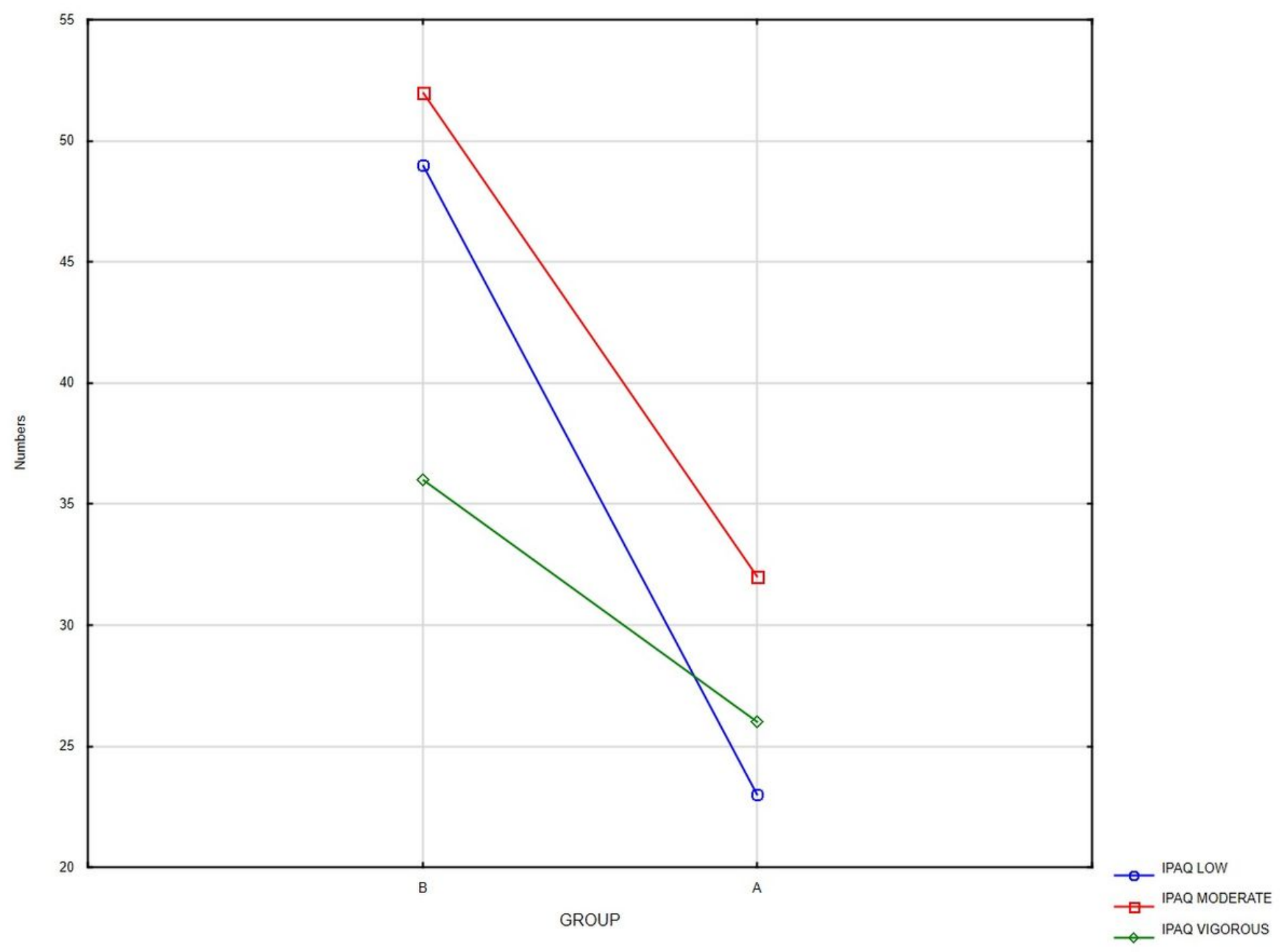

Figure 1

Physical activity level in examined groups $(A=$ main group with AIS; $B=$ control group with normal body posture). 


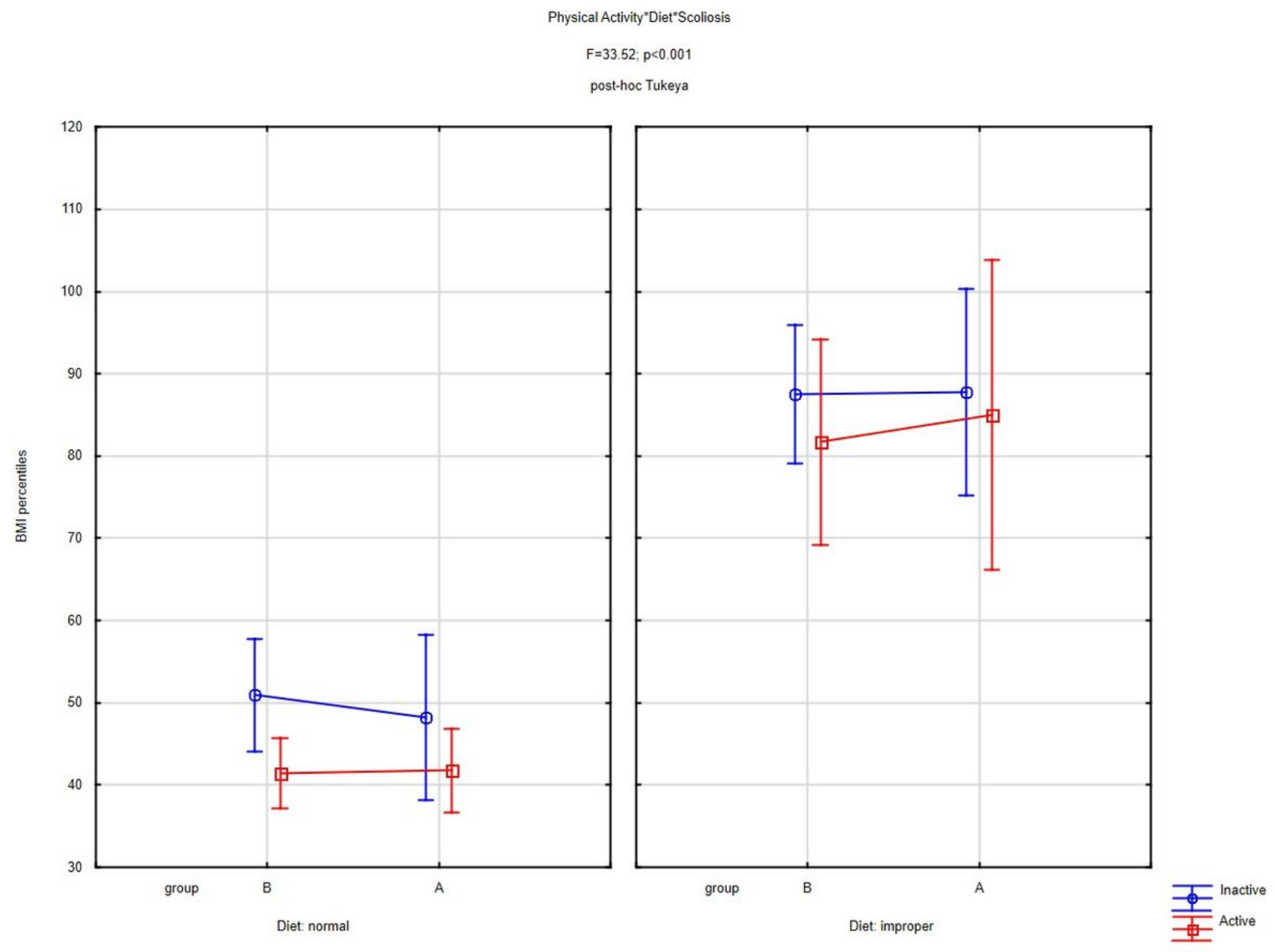

Figure 2

Average of $\mathrm{BMI}$ and interaction graphs of averages and interactions of factors such as scoliosis, physical activity levels and diet (analysis of variance ANOVA). 


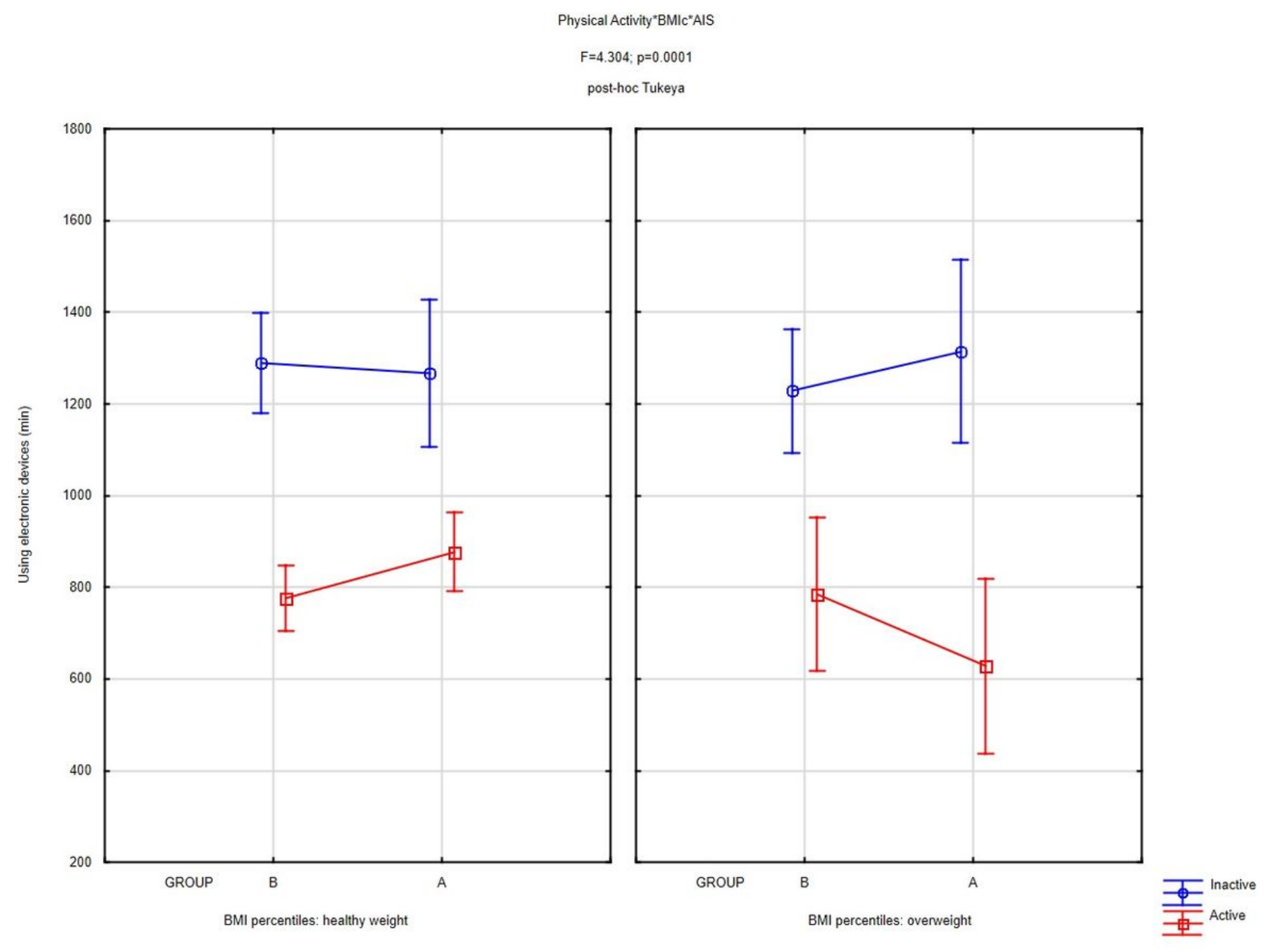

Figure 3

Average of time of using electronic devices and interaction graphs of averages and interactions of factors such as scoliosis, physical activity levels and BMI (analysis of variance ANOVA) 